\title{
Maximal expression of suppressors of cytokine signaling in the rat ovary occurs in late pregnancy
}

\author{
Stephen T Anderson ${ }^{1,2}$, Naajia N M Isa ${ }^{1}$, Johanna L Barclay ${ }^{1,3}$, Michael J Waters ${ }^{1,3}$ \\ and Jon D Curlewis ${ }^{1}$ \\ ${ }^{1}$ School of Biomedical Sciences, ${ }^{2}$ School of Animal Studies and ${ }^{3}$ Institute for Molecular Biosciences, The University of \\ Queensland, St Lucia, Queensland 4072, Australia
}

Correspondence should be addressed to S T Anderson at School of Biomedical Sciences, The University of Queensland; Email: stephen.anderson@uq.edu.au

\begin{abstract}
Maintenance of the rodent corpus luteum $(\mathrm{CL})$ during pregnancy requires prolactin receptor (PRLR) signal transduction via STAT5. At the end of pregnancy, prostaglandin $\mathrm{F} 2 \alpha\left(\mathrm{PGF}_{2 \alpha}\right)$ induces luteal regression through many mechanisms, including downregulation of PRLR signaling. We have previously shown that a $\mathrm{PGF}_{2 \alpha}$ analog upregulates suppressors of cytokine signaling (SOCS) proteins in the CL of day 19 pregnant rats leading to reduced STAT5 signaling. Here, we examined endogenous SOCS expression and STAT5 signaling in the rat ovary during normal pregnancy and luteolysis. The mRNA expression of Socs1, Socs2, and Socs3 and related cytokine-inducible SH2containing protein (Cish) was low in early pregnancy (day 7), but significantly increased at mid-pregnancy (days 10 and 13 ) associated with increased endogenous tyrosine phosphorylation (TyrP) of STAT5. In support of the notion that these changes are due to increasing placental lactogen levels at this time, we found that treatment with exogenous PRL on day 7 increased TyrP of STAT5 and induced SOCS mRNA expression, except Socs3. After mid-pregnancy, further significant increases in Socs3 and Cish mRNA expression were observed. Such changes in mRNA expression correlated with protein levels, with protein levels of both SOCS3 and CISH being maximal in late pregnancy (days 19-21). In addition, a significant reduction in TyrP of STAT5 was first observed on day 20, with a further substantial decrease on day 21. Therefore, these results are consistent with the hypothesis that increased SOCS expression in the rat ovary during late pregnancy reduces STAT5 signaling, which may be important in $\mathrm{PGF}_{2 \alpha}$-induced luteolysis.

Reproduction (2009) 138 537-544
\end{abstract}

\section{Introduction}

In rodents, the secretion of progesterone by the corpus luteum $(\mathrm{CL})$ is essential for normal pregnancy, with progesterone playing critical roles in embryo implantation, decidualization of the endometrial stroma, and maintenance of a quiescent myometrium before term. Luteotrophic support for the $\mathrm{CL}$ in early pregnancy is provided by pituitary prolactin (PRL; reviewed in Risk \& Gibori (2000)). Twice daily surges of PRL induced by the mating stimulus enhance $C L$ development and maintain progesterone secretion until mid-pregnancy, after which placental lactogens $(\mathrm{PL})$ become the major luteotrophic support to term.

The luteotrophic effects of both PRL and PL on the $\mathrm{CL}$ are mediated via the PRL receptor (PRLR), a member of the cytokine class 1 receptor family (Clevenger \& Kline 2001). In rodents, both the long (PRLRL) and short (PRLRS) PRLR variants are continuously expressed throughout gestation in the CL (Telleria et al. 1997). However, the PRLRL variant is more highly expressed at all stages of pregnancy and PRL signal transduction occurs predominantly via JAK2 and STAT pathways. The importance of PRL and its receptor in maintaining the $\mathrm{CL}$ of pregnancy in rodents was demonstrated in studies with neutralizing antisera to PRL (Yoshinaga 1974) and more recently in both PRL and PRLR knockout mice (Horseman et al. 1997, Ormandy et al. 1997). Moreover, STAT5B appears to be the key signaling intermediate in PRLR signal transduction in the CL, as STAT5B-deficient mice abort mid-pregnancy due to reduced progesterone levels (Udy et al. 1997) while STAT5A/B double knockout mice fail to form or maintain a $\mathrm{CL}$ (Teglund et al. 1998).

The maintenance of $\mathrm{CL}$ function, in particular progesterone production, by PRL is thought to involve a wide range of complimentary effects (for review see (Risk \& Gibori 2000)). One important element in the luteotrophic actions of PRL is thought to be the suppression of $20 \boldsymbol{\alpha}$-hydroxysteroid dehydrogenase (20 $\alpha \mathrm{HSD})$, which metabolizes progesterone to inactive $20 \alpha$-hydroxyprogesterone. In rodents, little 20 $\alpha \mathrm{HSD}$ activity is normally found in the $\mathrm{CL}$ during pregnancy, except immediately before parturition when 20 $\alpha \mathrm{HSD}$ 
expression rises rapidly, coincident with the fall in progesterone levels (Stocco et al. 2000). This appears to be important for normal parturition as 20aHSDdeficient mice exhibit sustained progesterone levels and a delay in parturition (Piekorz et al. 2005), although such marked effects were not observed recently in another line of $20 \alpha \mathrm{HSD}$-deficient mice (Ishida et al. 2008). Nevertheless, PRL activation of STAT5B appears important in suppressing $20 \alpha H S D$ gene expression and maintaining progesterone levels, as early abortion in STAT5B-deficient mice can be partially corrected by 20aHSD deficiency (Piekorz et al. 2005).

At the end of pregnancy, luteolysis occurs in response to increasing secretion of uterine prostaglandin $\mathrm{F} 2 \alpha$ $\left(\mathrm{PGF}_{2 \alpha}\right)$. A key component in luteal regression is the decline in progesterone levels (functional luteolysis), which is not observed in the $\mathrm{PGF}_{2 \alpha}$ receptor knockout mouse. The mechanisms by which $\mathrm{PGF}_{2 \alpha}$ induces functional luteolysis have been intensively investigated (for review see (Stocco et al. 2007)), but the initiating molecular events that result in a decline in progesterone secretion by the $\mathrm{CL}$ remain somewhat elusive. One early event involves upregulation of $20 \alpha \mathrm{HSD}$ by the transcription factor NUR77, which is absent in the $\mathrm{PGF}_{2 \alpha}$ receptor knockout mouse (Stocco et al. 2000). However, there is also a reduction in luteotrophic signaling to the $C L$ via the PRLR. Recent gene array data have shown opposite effects of $\mathrm{PGF}_{2 \alpha}$ and PRL on many genes in the rodent $C L$ suggesting a functional antagonism between these two hormones (Stocco et al. 2001). Indeed, as noted above, the expression of both PRLR variants in the CL decreases abruptly in late pregnancy (Telleria et al. 1997, Russell \& Richards 1999), an effect that has been shown to be $\mathrm{PGF}_{2 \alpha}$ dependent (Stocco et al. 2003). Furthermore, besides a reduction in PRLR expression, downstream signaling via STAT5 appears curtailed. We have shown (Curlewis et al. 2002) that administration of the $\mathrm{PGF}_{2 \alpha}$ receptor analog, cloprostenol, to day 19 pregnant rats induces expression of members of the suppressors of cytokine signaling (SOCS) protein family, which are well known to inhibit PRLR signal transduction via JAK2/STAT pathways. Specifically, we have shown increased expression of SOCS3 and to a lesser extent SOCS1 in response to cloprostenol, and this is coincident with decreased tyrosine phosphorylation (TyrP) and nuclear translocation of STAT5, many hours before a reduction in PRLR levels. Therefore, we hypothesize that the induction of SOCS proteins by $\mathrm{PGF}_{2 \alpha}$ and the consequent inhibition of PRLR signal transduction via STAT5 are critical early events in functional luteolysis. In the present study, we aimed to characterize the expression of endogenous SOCS proteins and examine STAT5 signal transduction in the rat ovary during normal pregnancy.

\section{Results}

\section{SOCS expression in the ovary during pregnancy}

The mRNA expression of all SOCS examined (Socs1, Socs2, Socs3, and cytokine-inducible $\mathrm{SH}$ 2-containing protein (Cish)) was the lowest on day 7 of pregnancy (Fig. 1). In general, SOCS mRNA expression significantly increased from early (day 7) to mid-pregnancy (day 10-13), and thereafter either remained at mid-pregnancy levels (Socs1 and Socs2) or increased further during late pregnancy (Socs3 and Cish). Nevertheless, mRNA expression of all SOCS examined was high in late
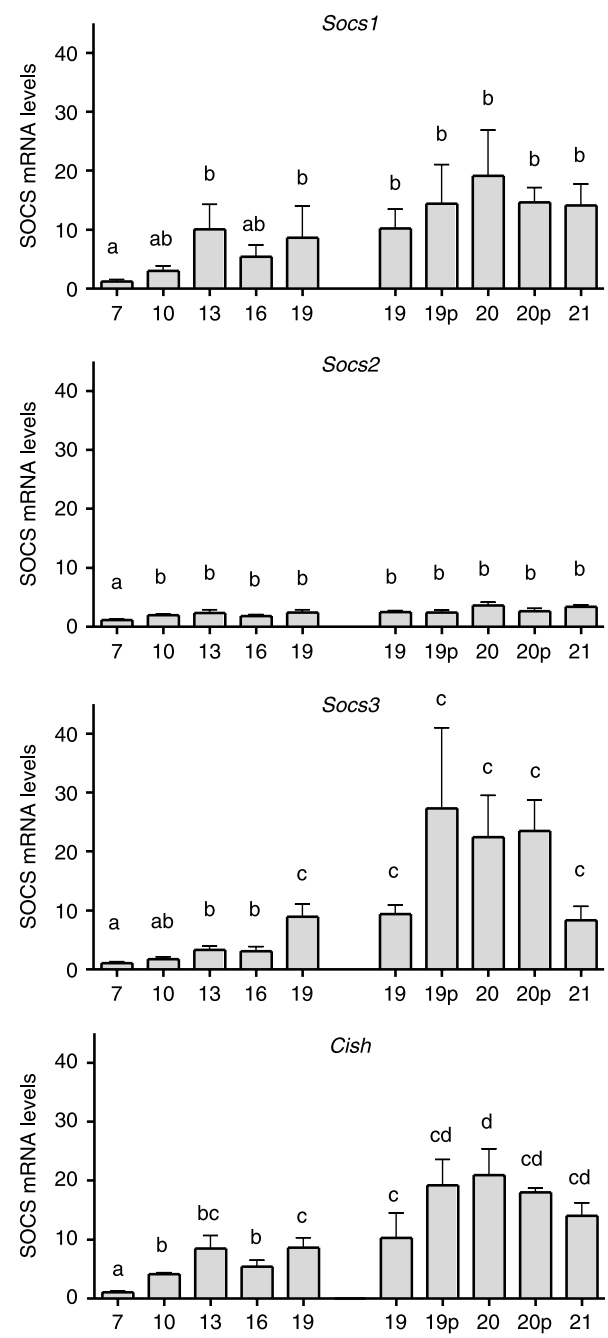

Figure 1 Ovarian SOCS mRNA expression increases during pregnancy. Total RNA was extracted from the ovaries of pregnant rats, reversed transcribed, and SOCS expression determined by real-time qPCR as described in Materials and Methods. SOCS results were normalized relative to $\beta$-actin and are expressed as the fold induction relative to day 7 of pregnancy. Samples were collected and processed as two separate sets (days 7-19 and days 19-21). Samples were obtained in the morning (1100-1200 h) on all days, with additional samples obtained at night (2300-2400 h) in late pregnancy (denoted P). Bars represent means \pm s.E.M. $(n=5$ rats per day). Different superscripts denote a significant difference $(P<0.05)$. 
pregnancy (days 19-21). Overall, the induction of Socs1, Socs2, and Cish across pregnancy was more marked (20- to 30-fold) than the induction of Socs2 ( $\sim$-fold).

For Socs3, a progressive increase in mRNA expression was observed across pregnancy, with significant $(P<0.05)$ increases from day 7 to 13 and day $16-19$ (Fig. 1). In late pregnancy (days 19-21), there was a trend (ANOVA, $P=0.06$ ) for increasing Socs3 mRNA expression. Levels increased from the morning of day 19 into the evening of the same day, and remained high on day 20 before declining on the morning of day 21 . However, there was marked variation in Socs3 mRNA expression between animals in late pregnancy.

For Cish, like Socs3, significant increases in mRNA expression were observed during pregnancy, although an unusual pattern was observed in the second half of pregnancy. Increased Cish mRNA expression was observed from day 7 to 13 , before a slight decrease on day 16 , followed by a return to higher expression on the morning of day 19. Thereafter, Cish mRNA expression significantly $(P<0.05)$ increased reaching maximal levels on the morning of day 20 and remained high through to day 21 (Fig. 1).

To confirm that the increase in Socs3 and Cish mRNA expression during pregnancy results in increased protein expression, western blots were conducted on whole-cell extracts (Fig. 2). In general, induction of SOCS3 and $\mathrm{CISH}$ protein levels during pregnancy correlated with changes in mRNA expression described above. SOCS3 protein levels were very low on day 7 of pregnancy, significantly increased on day 13 , further increased on day 19, and maximal on day 20 (Fig. 2A). Similarly CISH protein levels significantly increased during pregnancy, from low levels on day 7 to high levels in late pregnancy on days 19-21 (Fig. 2B).

\section{TyrP of STAT5 (early to mid-pregnancy)}

Since it is generally accepted that STATs increase SOCS expression, and then SOCS in turn act to limit further STAT signaling, it was of interest to examine endogenous STAT 5 signaling in the ovary from early to mid-pregnancy. We therefore performed IP/WB on whole-cell extracts of ovaries from the same animals used for quantitative realtime (qPCR) above. Results show low amounts of TyrP STAT 5 on day 7 , while on days 10 and 13 TyrP STAT5 was readily detectable (Fig. 3A). Quantitation of all replicates revealed significantly $(P<0.05)$ higher levels of TyrP on both days 10 and 13 compared with day 7 (Fig. 3A).

\section{Does activation of PRLR in early pregnancy activate STAT5 and upregulate SOCS expression in the ovary?}

At mid-pregnancy, increased endogenous TyrP of STAT5 together with increased SOCS expression in the ovary above is most likely a consequence of increasing
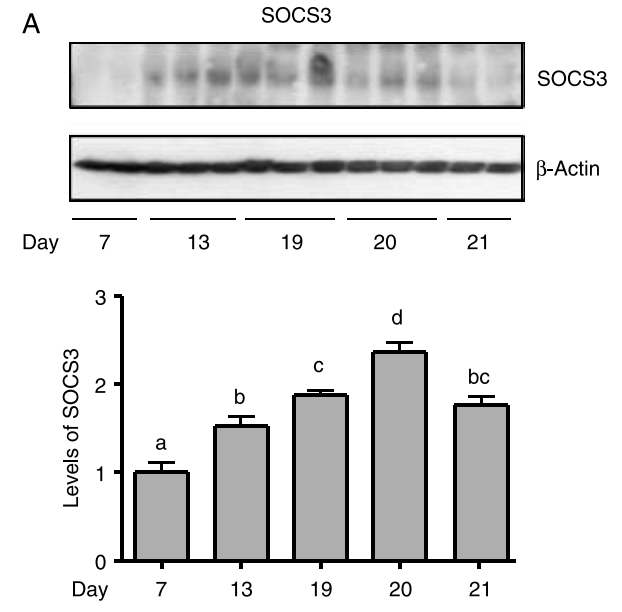

B
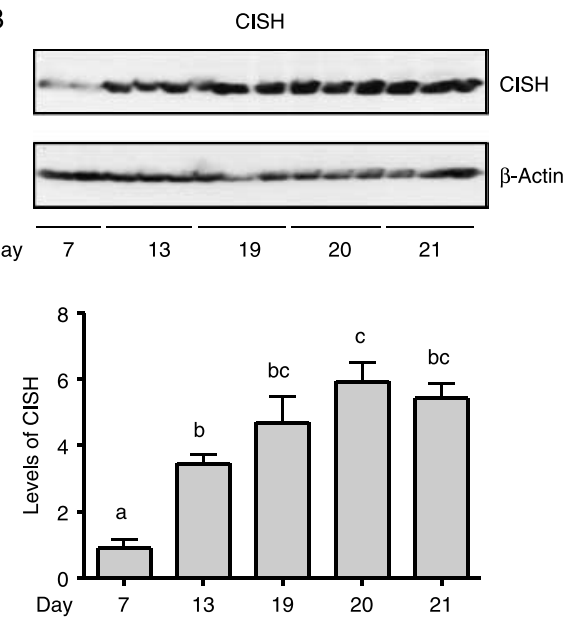

Figure 2 Ovarian SOCS3 and CISH protein levels increase during pregnancy and are maximal in late pregnancy. SOCS3 and $\mathrm{CISH}$ protein levels were determined by western blot on whole-cell extracts as described in Materials and Methods. Membranes were then stripped and reprobed for $\beta$-actin to confirm loading. Representative blots showing SOCS3 (A) and CISH (B) levels from day 7 to 21 and corresponding $\beta$-actin in same samples. Histograms show quantitation of western blots for all replicates. Results show the ratio of SOCS3 to $\beta$-actin and normalized relative to day 7 of pregnancy. Different superscripts denote a significant $(P<0.05)$ difference. Bars represent means \pm S.E.M. $(n=4-6$ rats per day).

secretion of PL acting via the PRLR. Since manipulating $P L$ is difficult, we examined whether activation of the PRLR by exogenous PRL in early pregnancy (day 7) increased TyrP STAT5 and SOCS expression.

In vehicle-treated rats on day 7, TyrP STAT5 again was low and difficult to detect (Fig. 4A). However, at 30 and 60 mins after $125 \mu \mathrm{g}$ ovine PRL (oPRL) injection, prominent TyrP STAT5 was observed (Fig. 4A). Quantitation of all samples at each time point revealed that oPRL significantly $(P<0.01)$ induced TyrP STAT5 compared to vehicle-treated animals at 30 and 60 mins, but the effect was transient with no significant treatment effect observed at 120 mins (Fig. 4B). 


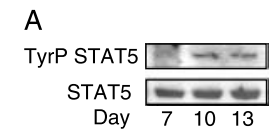

B
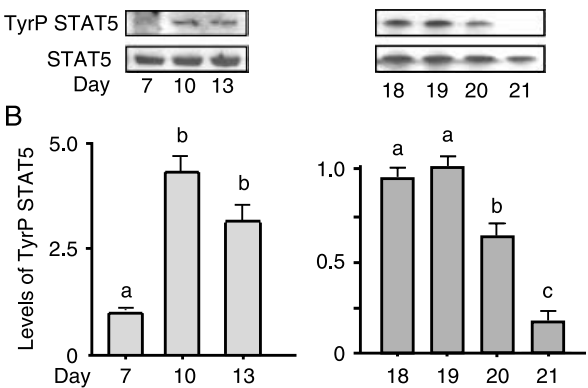

Figure 3 Tyrosine phosphorylation of STAT5 in rat ovary increases from early to mid-pregnancy, but declines during late pregnancy. Whole-cell extracts were immunoprecipitated for STAT5 before western blot with anti-phosphotyrosine antibody 4G10 as described in Materials and Methods. (A) Representative blots showing TyrP of STAT5 from individual animals (upper panel) and STAT5 loading (lower panel). (B) Quantitation of western blots for all replicates. Results show the ratio of TyrP STAT5 to STAT5 loading, and normalized relative to either day 7 or day 19 of pregnancy. Different superscripts denote a significant $(P<0.001)$ difference. Bars represent means \pm S.E.M. $(n=5-6$ rats per day).

In the same animals, we also examined SOCS mRNA expression and surprisingly exogenous PRL had no effect on the mRNA expression of any SOCS at either 30 or 60 mins (Fig. 5). However, significant $(P<0.05)$ increases in Socs1, Socs2, and Cish mRNA expression were observed later at 120 mins, and notably Cish mRNA expression was increased more than 7.5-fold. In contrast, Socs3 mRNA expression was not significantly induced by exogenous PRL up to $120 \mathrm{~min}$ after injection.

\section{TyrP of STAT5 (mid- to late pregnancy)}

As pregnancy proceeds, increasing levels of endogenous SOCS expression possibly function to negatively regulate responses to high circulating levels of PL. Indeed, previous studies have shown diminished responses to exogenous PRL after mid-pregnancy (Russell \& Richards 1999). To confirm these results in our model, we examined TyrP of STAT5 in response to exogenous PRL in mid- and late pregnancy. In contrast to our results in early pregnancy (Fig. 4A and B), exogenous PRL did not increase TyrP of STAT5 60 min after injection on either day 13 or day 19 (Fig. 4C). Quantitation of all replicates revealed no significant effect on either day 13 (vehicle $1.00 \pm 0.07$ versus oPRL $0.84 \pm 0.06$ ) or day 19 (vehicle $1.00 \pm 0.36$ versus oPRL $0.91 \pm 0.23$ ) of pregnancy.

In late pregnancy, we propose that a reduction in luteotrophic support for the CL through STAT5 signaling is one of the mechanisms by which $\mathrm{PGF}_{2 \alpha}$ induces luteolysis (Curlewis et al. 2002). Therefore, we examined that endogenous TyrP of STAT5 in the late pregnant animals also used for qPCR analysis of SOCS mRNA expression (day 19, 20, and 21 samples). For comparison, we also obtained samples from other animals on the

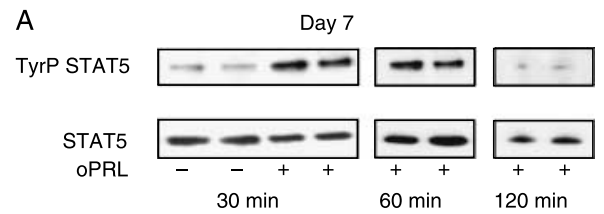

B
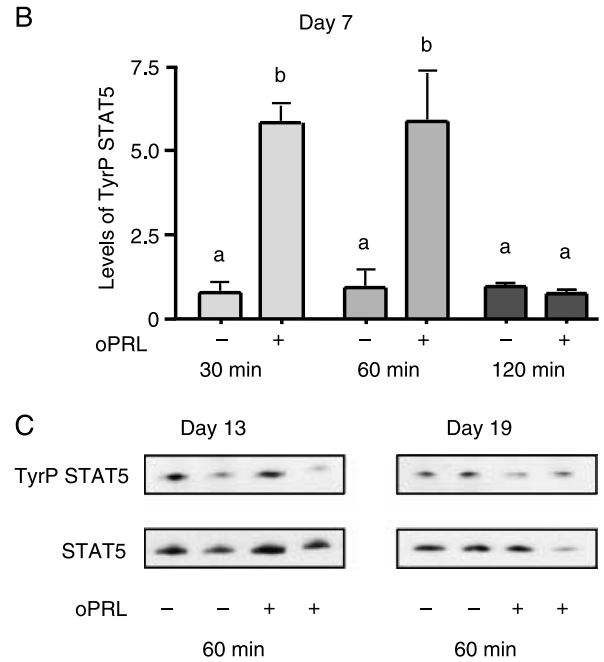

Figure 4 Exogenous PRL induces tyrosine phosphorylation of STAT5 in the ovary in early pregnancy (day 7 ), but not in mid- (day 13) or late (day 19) pregnancy. Rats on day 7 of pregnancy were given an s.c. injection of either vehicle or $125 \mu \mathrm{g}$ OPRL, and ovaries were collected at 30,60, and 120 min thereafter. Similarly in mid- (day 13) and late pregnancy (day 19), rats were treated with oPRL but ovaries were collected only at $60 \mathrm{~min}$ post-injection. Ovarian whole-cell extracts were immunoprecipitated for STAT5 before western blot with antiphosphotyrosine antibody 4G10 as described in Materials and Methods. (A and C) Representative western blots showing TyrP of STAT5 (upper panel) and STAT5 loading (bottom panel) from vehicle- or oPRLtreated animals. (B) Quantitation of western blots on day 7 of pregnancy. Results shown are the ratio of TyrP STAT5 to STAT5 loading, and normalized relative to vehicle. Different superscripts denote a significant $(P<0.05)$ difference. Bars represent means \pm S.E.M. $(n=4$ rats per treatment and time).

morning of day 18 of pregnancy. Representative blots show that TyrP of STAT5 was readily detectable on both days 18 and 19 (Fig. 3C). Quantitation of all replicates revealed that TyrP of STAT5 was not significant different between days 18 and 19 , but thereafter levels significantly $(P<0.01)$ declined on day 20 , and further on day 21 (Fig. 3D).

\section{Discussion}

SOCS proteins are well established as negative regulators of cytokine signaling, with SOCS1-3 and CISH being important regulators of PRLR signal transduction via JAK2/STAT pathways. In this study, we have shown that expression of these SOCS significantly increases in the ovary as pregnancy progresses. Furthermore, in late pregnancy around the time of functional luteolysis, we observed reduced TyrP of STAT5 concurrent with maximal mRNA expression of SOCS. Given the critical 

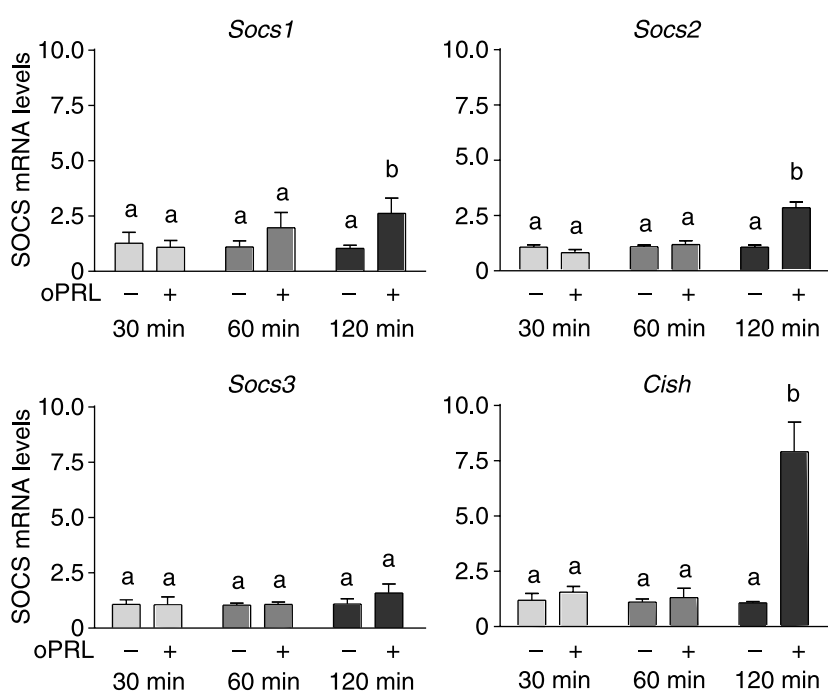

Figure 5 Exogenous PRL induces SOCS mRNA expression in the ovary during early pregnancy. Day 7 pregnant rats were given an s.c. injection of either saline vehicle or $125 \mu \mathrm{g}$ oPRL, and ovaries were collected 30 , 60 , and 120 mins later. Total RNA was isolated, reversed transcribed, and SOCS genes amplified using real-time qPCR as described in Materials and Methods. Data are expressed relative to $\beta$-actin and normalized relative to vehicle treatment. Different superscripts denote a significant $(P<0.05)$ difference. Bars represent means \pm S.E.M. $(n=4$ rats per treatment and time).

importance of PRLR signal transduction through STAT5 in maintaining progesterone output by the $C L$ of pregnancy in rodents, the present results are consistent with the idea that upregulation of SOCS proteins are a key element in $\mathrm{PGF}_{2 \alpha}$-induced luteolysis.

SOCS proteins are acutely upregulated in response to cytokine signaling, and essentially act to limit further signaling through JAK2/STAT pathways. In the present study, the significant increase in Socs1-3 and Cish mRNA levels in the ovary at mid-pregnancy (day 10 or 13) is most likely due to increasing secretion of PL. Around day 10 of pregnancy, luteotrophic support for the $\mathrm{CL}$ changes from PRL to $\mathrm{PL}$, with termination of the twice-daily surges of pituitary PRL and replacement with increasing continuous release of PL (Freeman \& Neill 1972). This change in ligand and/or pattern of secretion most likely increases PRLR-mediated signal transduction and SOCS expression. Indeed, we have found that increased SOCS expression at mid-pregnancy in the present study is associated with a significant increase in endogenous TyrP STAT5. This latter result is in accord with earlier studies that show increased constitutive STAT5 activity in the rat CL from day 10 of pregnancy (Russell et al. 1996, Russell \& Richards 1999). Therefore, PL most likely increases PRLR signal transduction via STAT5 and increases SOCS expression. While no study has directly shown regulation of SOCS expression by PL, in late pregnancy, increased SOCS expression in the arcuate nucleus of the hypothalamus has been noted in response to both PRL (PL) and estrogen (Steyn et al.
2008). However, this induction of SOCS in the hypothalamus is dependent upon declining progesterone levels. This is marked contrast to our observations in the ovary, where increased SOCS expression is associated with high endogenous levels of $\mathrm{PL}$, estrogen, and progesterone.

In the present study, we examined whether activation of the PRLR in early pregnancy would upregulate SOCS expression in the ovary. As expected, we observed that exogenous PRL rapidly (within 30 mins) induced TyrP of STAT5 in ovarian extracts on day 7 of pregnancy. However, surprisingly, the activation of STAT5 did not result in upregulation of SOCS mRNA expression by 60 mins, rather only later at 120 mins. Nevertheless, upregulation of SOCS mRNA expression at 120 mins was associated with decreased TyrP of STAT5 at this time, consistent with the idea that SOCS are negative regulators of STAT signaling. Most surprising was a lack of PRL-induced SOCS3 expression and rather minor (2.5-fold) responses in SOCS1 and SOCS2. Overall, these results contrast markedly with an earlier study (Tam et al. 2001), where oPRL injection rapidly (within 30 mins) and substantially (7- to 20-fold) induced ovarian SOCS mRNA expression. Differences in results likely reflect the animal models used, with the earlier study using non-pregnant lactating rats given bromocriptine to suppress endogenous PRL. In the present study, we did not use bromocriptine, but rather sampled animals in early pregnancy at a time of day (1100-1200 h) when circulating PRL concentrations are low, avoiding the endogenous PRL surges. Low endogenous SOCS expression in early pregnancy may be particularly important, as upregulation of ovarian SOCS1 and SOCS3 expression in the CL by proinflammatory cytokines has been recently linked to early pregnancy failure (Erlebacher et al. 2004).

As normal pregnancy progresses, increasing levels of endogenous SOCS expression in the CL may function to negatively regulate the cellular response to $\mathrm{PL}$ and thereby prevent overstimulation of the JAK2/STAT signal transduction pathways. Previous studies have established that administration of exogenous PRL does not increase STAT5 DNA binding in the CL after mid-pregnancy, when constitutive activity is present (Russell \& Richards 1999). Moreover, constitutive nuclear STAT5 binding is itself reduced from day 17 (Russell \& Richards 1999), despite continued elevated levels of PL around this time (Robertson \& Friesen 1981). Essentially, as pregnancy progresses, the CL appears to develop a PRL-resistant state, at least in terms of PRLR signal transduction via STAT5. Our current SOCS results provide a possible physiological basis for this loss of STAT5 responsiveness in the CL. Previous work has shown that the luteal expression of key PRLR-signaling molecules, JAK2 and STAT5, is not limiting up to day 21 of pregnancy (Russell et al. 1996). Indeed, these authors conclude that in late pregnancy, the decrease in responsiveness of luteal 
cells to PRL occurs at a point in the signaling pathway between the receptor and STAT proteins. We now suggest that the progressive increases in SOCS3 and CISH expression during pregnancy together with maintained (mid-pregnancy) levels of SOCS1 and SOCS2 expression, as noted in the present study, limit the responsiveness of the $\mathrm{CL}$ to $\mathrm{PL}$ as pregnancy proceeds.

In late pregnancy, the relatively high expression of all SOCS examined, together with a significant decline in TyrP STAT5 at this time, suggests that SOCS proteins may be an important element in $\mathrm{PGF}_{2 \alpha}$-induced luteolysis. It is of interest to consider the pattern of SOCS expression relative to the time at which endogenous $\mathrm{PGF}_{2 \alpha}$ levels begin to increase. Most studies in rats indicate that $\mathrm{PGF}_{2 \alpha}$ is increased on day 19 or 20 of pregnancy and then further increases close to term (Labhsetwar \& Watson 1974, Shaikh et al. 1977, Wilson et al. 1982). However, the exact timing of increased uterine $\mathrm{PGF}_{2 \alpha}$ secretion is difficult to determine due to the pulsatile pattern of $\mathrm{PGF}_{2 \alpha}$ release. Interestingly, some studies have shown small but significant increases in $\mathrm{PGF}_{2 \alpha}$ levels as early as day 16 of pregnancy (Puri \& Garfield 1982). In relation to our SOCS results, we observed significant increases in both Socs3 and Cish mRNA expression from day 16 to 19 , then a further significant increase from day 19 to 20 for $\mathrm{CISH}$. Furthermore, our western blot data show that SOCS3 and CISH protein levels are maximal in late pregnancy (days 19-21). In contrast, Socs1 and Socs2 mRNA expression did not significantly change at these times, remaining at mid-pregnancy levels. Therefore, these results suggest that $\mathrm{PGF}_{2 \alpha}$ may specifically upregulate SOCS3 and CISH expression in the CL. In support of this hypothesis, we have previously shown by immunohistochemistry that both SOCS3 and CISH are predominantly localized to the $\mathrm{CL}$ in the rat ovary (Tam et al. 2001, Curlewis et al. 2002), and moreover that administration of the PGF analog cloprostenol to rats on day 19 causes a rapid and sustained increase in SOCS3 mRNA and protein expression in luteal cells (Curlewis et al. 2002). However, cloprostenol did not increase Cish mRNA expression. While this may suggest that high levels of endogenous $\mathrm{CISH}$ expression observed in the present study are not due to $\mathrm{PGF}_{2 \alpha,}$ it should be noted that here we quantitated Cish mRNA by qPCR, a far more sensitive method than by northern blot used in our previous study (Curlewis et al. 2002). Future studies examining the induction of SOCS in luteal cells in response to $\mathrm{PGF}_{2 \alpha}$ would be useful. Nevertheless, functional luteolysis may require the combined inhibitory actions of a number of SOCS proteins. Interestingly, a line of SOCS2-deficient mice exhibits a small delay (about 1 day) in parturition, but otherwise gives birth normally (Cargill et al. 2000, Corva et al. 2004). In contrast, CISH null mice display no obvious reproductive phenotype, while an essential role of
SOCS3 in luteolysis remains unknown, as SOCS3 null mice die in utero (Marine et al. 1999). Further work closely examining the luteal function in SOCS knockout mice, particularly mice deficient in several SOCS genes, may reveal redundant roles for individual SOCS proteins in luteolysis. Also characterization of endogenous SOCS expression in the $\mathrm{CL}$ of pregnant $\mathrm{PGF}_{2 \alpha}$ receptor knockout mice would be helpful.

One mechanism of action of SOCS proteins, which may be important in functional luteolysis, is the targeting of PRLR for proteasomal degradation (Zhang et al. 1999). Indeed, as mentioned earlier, downregulation of PRLR appears to be an important part of $\mathrm{PGF}_{2 \alpha}$-induced luteolysis. However, this only occurs immediately prior to parturition (Telleria et al. 1997). Furthermore, while PRLR downregulation undoubtedly limits the luteotrophic effects of $\mathrm{PRL} / \mathrm{PL}$, we suggest that a reduction in PRLR is an event subsequent to and a consequence of increased SOCS expression. We have previously shown that cloprostenol induces SOCS expression and inhibits TyrP and nuclear translocation of STAT5 some $8 \mathrm{~h}$ before any loss in PRLR expression (Curlewis et al. 2002). In the present study, we show that endogenous TyrP of STAT5 is initially reduced on day 20 of gestation, 1 day before any decrease in PRLR (Telleria et al. 1997). Also PRLR expression itself is thought to be a downstream effect of PRLR signal transduction by STAT5 (Galsgaard et al. 1999). Therefore, our hypothesis is that the inhibition of PRLR signal transduction through STAT5 is caused initially by $\mathrm{PGF}_{2 \alpha}$-induced SOCS expression, followed by a downregulation of PRLR expression and these events reduce luteotrophic support for the CL.

\section{Materials and Methods}

\section{Materials}

oPRL-20 was obtained from the National Hormone and Peptide Program (Baltimore, MD, USA). Goat anti-SOCS3 (sc 7009), rabbit anti-STAT5 (sc $835 \times$ ), and rabbit anti-CISH (sc 15344) were purchased from Santa Cruz Biotechnology, Inc. (Santa Cruz, CA, USA). Mouse monoclonal anti- $\beta$-actin (A 5441) was obtained from Sigma-Aldrich. ECL peroxidase anti-mouse antibody (NA931VS) and ECL peroxidase anti-rabbit antibody (NA931VS) were obtained from Amersham Pharmacia Biotech. HRP-conjugated rabbit anti-goat antibody (31402) was purchased from Pierce Chemical Co. (Rockford, IL, USA). Anti-phosphotyrosine 4G10 (28818) was obtained from Upstate (Lake Placid, NY, USA). Analytical reagent grade chemicals were purchased either from the Sigma-Aldrich or Ajax Chemical Co. (Auburn, NSW, Australia).

\section{Animals}

Wistar rats were housed at $24^{\circ} \mathrm{C}$ with a $12 \mathrm{~h}$ light: $12 \mathrm{~h}$ darkness cycle (lights on 0500-1900 h) and allowed free excess to rat chow and water. For mating, females (8-10 weeks of age) were housed overnight with males and checked the following morning 
for a vaginal plug (designated as day 1 of pregnancy). In our colony, Wistar rats normally give birth on day 21 or 22 . Rats were killed by spinal dislocation at various times during pregnancy (between days 7 and 21) between 1100 and 1200 (morning) to avoid the endogenous PRL surges. In late pregnancy, additional samples were obtained between 2300 and $2400 \mathrm{~h}$ (evening). In some experiments, pregnant rats were given a s.c. injection of $125 \mu \mathrm{g}$ oPRL or vehicle (saline) at 1000-1030 $\mathrm{h}$ and killed 30-120 min later. Following death, the ovaries were quickly removed and trimmed of adhering fat and connective tissue. Ovaries were then dissected in half by counting corpora lutea and then one half from each ovary was pooled together for either RNA or protein extraction. During dissection of the ovary, most interstitial tissue was removed before the remaining tissue (principally corpora lutea) was frozen on solid $\mathrm{CO}_{2}$ and stored at $-80{ }^{\circ} \mathrm{C}$ until required. Animals with less than five corpora lutea on an ovary were not used. These experiments were approved by the University of Queensland Institutional Animal Ethics Committee according to National Health and Medical Research Councils (Australia) guidelines.

\section{$R N A$ extraction and $R T$}

Total RNA was isolated from ovarian tissue using TRIzol Reagent (Gibco BRL) as previously described (Curlewis et al. 2002). Samples were DNAse treated before RT using Superscript II preamplification kit according to the manufacturer's instructions (Gibco BRL) with random hexamer primers.

\section{Quantitative real-time PCR}

For qPCR, CDNA was diluted 1:20 in water and PCR performed using $5 \mu$ liluted cDNA, $3 \mu \mathrm{M}$ and $2 \mu \mathrm{M}$ Taqman probes for $\beta$-actin, and each SOCS respectively $2 \mu \mathrm{M}$ primers and $13 \mu \mathrm{l}$ Taqman Master Mix in a $25 \mu \mathrm{l}$ volume. Cish forward primer 5'ccgactggactccaattgct3', Cish reverse primer 5'ctgcacaaggctgaccacat3', Cish probe 6-FAM-agacctcgaatcctggccttccca3'TAMRA; Socs 1 forward primer 5'ccgtgggtcgcgagaac $3^{\prime}$, Socs 1 reverse primer 5'aaggaactcaggtagtcacggagta3', Socs 1 probe 6-FAM-tggcgcgcatccctcttaaccc3'-TAMRA; Socs2 forward primer 5'aagcacgcgaggtcctttg $3^{\prime}$, Socs2 reverse primer 5'gatgagtcaacacgtccaagaca3', Socs2 probe 6-FAM-ccccagctcgggcgaccac3'-TAMRA; Socs3 forward primer 5'aaaatccagccccaatgg $3^{\prime}$, Socs 3 reverse primer $5^{\prime}$ ggcctgaggaagaagcctatc $3^{\prime}$, Socs3 probe 6-FAM-cggtagctcccagttagcccagcag3'-TAMRA; $\beta$-actin forward primer $5^{\prime}$ ttcaacacccagccatgt3', $\beta$-actin reverse primer $5^{\prime}$ cagtggtacgaccagaggcata $3^{\prime}, \beta$-actin probe 6-FAM-cgtagccatccagctgtgttgtccc3'-TAMRA. Each sample was analyzed in triplicate by qPCR using the ABI prism 7000 Taqman Real-Time PCR machine (Applied Biosystems, Foster City, CA, USA). Negative controls were included in all qPCR runs by substituting CDNA with RNase-free water. Analysis was performed by normalizing the SOCS signal to $\beta$-actin for each sample, then levels were expressed as the relative change (comparative $C_{\mathrm{t}}$ method) compared with levels on either day 7 (early pregnancy) or day 19 (late pregnancy), or vehicle treatment depending on the experiment. Coefficients of variation within sample triplicates were $<1 \%$.

\section{Protein extraction, immunoprecipitation, and western blots}

Frozen ovarian tissue was homogenized in TK lysis buffer (50 mM HEPES (pH 7.4), $150 \mathrm{mM} \mathrm{NaCl}, 1 \%$ Triton-X-100, $30 \mathrm{mM} \mathrm{NaF}, 10 \mathrm{mM} \mathrm{Na}_{2} \mathrm{P}_{2} \mathrm{O}_{7}, 10 \mathrm{mM}$ EDTA, and $1 \mathrm{mM}$ $\mathrm{Na}_{2} \mathrm{VO}_{3}$ ) with complete protease inhibitor cocktail (\#1697498, Roche). Homogenates were centrifuged at $15000 \mathrm{~g}$ for $15 \mathrm{mins}$ at $4{ }^{\circ} \mathrm{C}$ and the supernatant removed, and stored at $-80{ }^{\circ} \mathrm{C}$ until required. Total protein in tissue lysates was determined using the bicinchoninic acid protein assay as per the manufacturer's instructions (Pierce Chemical).

Protein A beads were washed twice in PBS and blocked in $1 \%$ BSA in TBS with $0.1 \%$ Tween-20 (TBST) for $1 \mathrm{~h}$ at room temperature with rotation. Beads were washed in PBS and in TK lysis buffer without inhibitors (TK-), and $2 \mu \mathrm{g}$ of STAT5 antibody (sc $835 \times$ ) in TK - were bound overnight at $4{ }^{\circ} \mathrm{C}$ with rotation. Following this, beads were washed in PBS and twice in TK-, before the addition of $0.5 \mathrm{mg}$ of cell supernatant protein in $\mathrm{TK}+$ buffer for $2 \mathrm{~h}$ at $4{ }^{\circ} \mathrm{C}$ with rotation. Beads were again washed thrice in $\mathrm{TK}+$, all traces of liquid were removed from the beads, and bound proteins were eluted in sample buffer (15 mM Tris- $\mathrm{HCl}$ (pH 6.8), 2\% SDS, 10\% glycerol, and $10 \mathrm{mM}$ dithiothreitol) at $100{ }^{\circ} \mathrm{C}$ for 5 mins. Samples were loaded onto 8\% SDS-PAGE gels and electrophoresed for $2 \mathrm{~h}$ at $90 \mathrm{~V}$ in $1 \times$ SDS Lamelli buffer.

After electrophoresis, gels were equilibrated in transfer buffer (15\% methanol in $1 \times$ SDS buffer) before being transferred onto PVDF membrane by an electroblotter (Amersham Pharmacia Biotech). Membranes were blocked in 2\% BSA in TBST for $1 \mathrm{~h}$ at room temperature, before being incubated overnight with primary antibody (phosphotyrosine antibody, 4G10) at 1:1000 dilution in blocking buffer with rocking at $4{ }^{\circ} \mathrm{C}$. Membranes were then washed in TBST, and incubated with secondary antibody (ECL peroxidase anti-mouse antibody at 1:10 000) for $2 \mathrm{~h}$ at room temperature with rocking. Membranes were washed as before, and ECL Plus Western Blot detection system (Amersham Pharmacia Biotech) used as per the manufacturer's instructions to develop signal. To determine STAT5 protein loading, membranes were incubated in stripping buffer $(2.8 \mathrm{ml}$ $1 \mathrm{M}$ Tris, $42.2 \mathrm{ml}$ deionized water, $5 \mathrm{ml}$ of $20 \% \mathrm{SDS}$, and $350 \mathrm{ul} \beta$-mercaptoethanol, $\mathrm{pH}$ 6.8) for $20 \mathrm{mins}$ at $60{ }^{\circ} \mathrm{C}$, extensively washed in TBST, then reprobed with primary STAT5 antibody (sc $835 \times)$ at 1:10 000 overnight at $4{ }^{\circ} \mathrm{C}$ before secondary antibody ( $\mathrm{ECL}$ peroxidase anti-rabbit antibody at 1:5000), and developed as described above.

For SOCS3 and CISH western blots, $50 \mu \mathrm{g}$ of ovarian lysates were electrophoresed on a 12\% SDS-PAGE gel and then transferred on to PVDF membranes. The membranes were blocked with $5 \%$ skin milk in TBST, before being incubated with primary goat anti-SOCS3 antibody (sc 7009) at 1:500 or rabbit anti-CISH (sc 15344) at 1:1000 both diluted in blocking buffer. Thereafter, membranes were incubated with either HRPconjugated rabbit anti-goat (1:5000) or ECL peroxidase antirabbit (1:10 000) secondary antibody diluted in blocking buffer. To ensure equal loading of protein in each sample, membranes were stripped and reprobed with anti- $\beta$-actin (A 5441) antibody, followed by secondary ECL peroxidase anti-mouse antibody (1:10 000) and development as described above. 


\section{Statistical analysis of data}

One-way ANOVA was used to analyse the data, followed by post hoc Newman-Keuls tests to examine individual comparisons. Data were log-transformed before analysis to remove heterogeneity of variance where appropriate. Values were considered statistically significant at $P<0.05$.

\section{Declaration of interest}

The authors declare that there is no conflict of interest that could be perceived as prejudicing the impartiality of the research reported.

\section{Funding}

This work was supported by the Australian Research Council.

\section{References}

Cargill SL, Medrano JF, Famula TR \& Anderson GB 2000 Effects of the high growth (hg) mutation on reproduction in high growth (HG) female mice. Growth, Development, and Aging 64 21-31.

Clevenger CV \& Kline JB 2001 Prolactin receptor signal transduction. Lupus $10706-718$.

Corva PM, Mucci NC, Evans K \& Medrano JF 2004 Diet effects on female reproduction in high growth $(\mathrm{hg} / \mathrm{hg})$ mice that are deficient in the Socs-2 gene. Reproduction, Nutrition, Development 44 303-312.

Curlewis JD, Tam SP, Lau P, Kusters DH, Barclay JL, Anderson ST \& Waters MJ 2002 A prostaglandin $f(2 \alpha)$ analog induces suppressors of cytokine signaling-3 expression in the corpus luteum of the pregnant rat: a potential new mechanism in luteolysis. Endocrinology 143 3984-3993.

Erlebacher A, Zhang D, Parlow AF \& Glimcher LH 2004 Ovarian insufficiency and early pregnancy loss induced by activation of the innate immune system. Journal of Clinical Investigation 114 39-48.

Freeman ME \& Neill JD 1972 The pattern of prolactin secretion during pseudopregnancy in the rat: a daily nocturnal surge. Endocrinology $\mathbf{9 0}$ 1292-1294.

Galsgaard ED, Nielsen JH \& Moldrup A 1999 Regulation of prolactin receptor (PRLR) gene expression in insulin-producing cells. Prolactin and growth hormone activate one of the rat prlr gene promoters via STAT5a and STAT5b. Journal of Biological Chemistry 274 18686-18692.

Horseman ND, Zhao W, Montecino-Rodriguez E, Tanaka M, Nakashima K, Engle SJ, Smith F, Markoff E \& Dorshkind K 1997 Defective mammopoiesis, but normal hematopoiesis, in mice with a targeted disruption of the prolactin gene. EMBO Journal 16 6926-6935.

Ishida M, Choi JH, Hirabayashi K, Matsuwaki T, Suzuki M, Yamanouchi K, Horai R, Sudo K, Iwakura Y \& Nishihara M 2008 Reproductive phenotypes in mice with targeted disruption of the $20 \alpha$-hydroxysteroid dehydrogenase gene. Journal of Reproduction and Development 53 499-508.

Labhsetwar AP \& Watson DJ 1974 Temporal relationship between secretory patterns of gonadotropins, estrogens, and prostaglandin- $\mathrm{F}$ in periparturient rats. Biology of Reproduction 10 103-110.

Marine JC, McKay C, Wang D, Topham DJ, Parganas E, Nakajima H, Pendeville H, Yasukawa H, Sasaki A, Yoshimura A et al. 1999 SOCS3 is essential in the regulation of fetal liver erythropoiesis. Cell 98 617-627.

Ormandy CJ, Camus A, Barra J, Damotte D, Lucas B, Buteau H, Edery M, Brousse N, Babinet C, Binart N et al. 1997 Null mutation of the prolactin receptor gene produces multiple reproductive defects in the mouse. Genes \& Development 11 167-178.

Piekorz RP, Gingras S, Hoffmeyer A, Ihle JN \& Weinstein Y 2005 Regulation of progesterone levels during pregnancy and parturition by signal transducer and activator of transcription 5 and $20 \alpha$-hydroxysteroid dehydrogenase. Molecular Endocrinology 19 431-440.
Puri CP \& Garfield RE 1982 Changes in hormone levels and gap junctions in the rat uterus during pregnancy and parturition. Biology of Reproduction 27 967-975.

Risk M \& Gibori G 2000 Mechanisms of luteal cell regulation by prolactin. In Prolactin, pp 265-295. Ed. ND Horseman. Boston: Kluwer Academic.

Robertson MC \& Friesen HG 1981 Two forms of rat placental lactogen revealed by radioimmunoassay. Endocrinology 108 2388-2390.

Russell DL \& Richards JS 1999 Differentiation-dependent prolactin responsiveness and stat (signal transducers and activators of transcription) signaling in rat ovarian cells. Molecular Endocrinology 13 2049-2064.

Russell DL, Norman RL, Dajee M, Liu X, Hennighausen L \& Richards JS 1996 Prolactin-induced activation and binding of stat proteins to the IL-6RE of the alpha 2-macroglobulin (alpha 2M) promoter: relation to the expression of alpha $2 \mathrm{M}$ in the rat ovary. Biology of Reproduction $\mathbf{5 5}$ 1029-1038.

Shaikh AA, Naqvi RH \& Saksena SK 1977 Prostaglandins E and F in uterine venous plasma in relation to peripheral plasma levels of progesterone and $20 \alpha$-hydroxyprogesterone in the rat throughout pregnancy and parturition. Prostaglandins 13 311-320.

Steyn FJ, Anderson GM \& Grattan DR 2008 Hormonal regulation of suppressors of cytokine signaling (SOCS) messenger ribonucleic acid in the arcuate nucleus during late pregnancy. Endocrinology 149 3206-3214.

Stocco CO, Zhong L, Sugimoto Y, Ichikawa A, Lau LF \& Gibori G 2000 Prostaglandin F2 $\alpha$-induced expression of $20 \alpha$-hydroxysteroid dehydrogenase involves the transcription factor NUR77. Journal of Biological Chemistry 275 37202-37211.

Stocco C, Callegari E \& Gibori G 2001 Opposite effect of prolactin and prostaglandin $F(2 \alpha)$ on the expression of luteal genes as revealed by rat cDNA expression array. Endocrinology 142 4158-4161.

Stocco C, Djiane J \& Gibori G 2003 Prostaglandin $F(2 \alpha)(\operatorname{PGF}(2 \alpha))$ and prolactin signaling: PGF $(2 \alpha)$-mediated inhibition of prolactin receptor expression in the corpus luteum. Endocrinology 144 3301-3305.

Stocco C, Telleria C \& Gibori G 2007 The molecular control of corpus luteum formation, function, and regression. Endocrine Reviews 28 117-149.

Tam SP, Lau P, Djiane J, Hilton DJ \& Waters MJ 2001 Tissue-specific induction of SOCS gene expression by PRL. Endocrinology 142 5015-5026.

Teglund S, McKay C, Schuetz E, van Deursen JM, Stravopodis D, Wang D, Brown M, Bodner S, Grosveld G \& Ihle JN 1998 Stat5a and Stat5b proteins have essential and nonessential, or redundant, roles in cytokine responses. Cell 93 841-850.

Telleria CM, Parmer TG, Zhong L, Clarke DL, Albarracin CT, Duan WR, Linzer DI \& Gibori G 1997 The different forms of the prolactin receptor in the rat corpus luteum: developmental expression and hormonal regulation in pregnancy. Endocrinology 138 4812-4820.

Udy GB, Towers RP, Snell RG, Wilkins RJ, Park SH, Ram PA, Waxman DJ \& Davey HW 1997 Requirement of STAT5b for sexual dimorphism of body growth rates and liver gene expression. PNAS 94 7239-7244.

Wilson L Jr, Stanisc D, Khan-Dawood F \& Dawood MY 1982 Alterations in reproductive tissue prostaglandins $\mathrm{E}$ and $\mathrm{F}, 6$-keto-prostaglandin $\mathrm{F} 1$ alpha and thromboxane B2 with gestational age in the rat. Biology of Reproduction 27 1207-1215.

Yoshinaga K 1974 Ovarian progestin secretion in lactating rats: effect of intrabursal injection of prolactin antiserum, prolactin and LH. Endocrinology 94 829-834.

Zhang JG, Farley A, Nicholson SE, Willson TA, Zugaro LM, Simpson RJ, Moritz RL, Cary D, Richardson R, Hausmann G et al. 1999 The conserved SOCS box motif in suppressors of cytokine signaling binds to elongins $\mathrm{B}$ and $\mathrm{C}$ and may couple bound proteins to proteasomal degradation. PNAS 96 2071-2076.

Received 9 October 2008

First decision 12 November 2008

Revised manuscript received 23 April 2009

Accepted 5 June 2009 